\title{
Problematization of the metaphysical foundations of human personality
}

\author{
Tatyana Torubarova ${ }^{1, *}$, Olga Dyachenko ${ }^{1}$ \\ ${ }^{1}$ Kursk State University, Kursk region, Russia
}

\begin{abstract}
In the presented article, the problem of the metaphysical foundations of human personality in the modern world is brought to the foreground. The relevance of the study is due to the presence in contemporary culture of the phenomenon of human self-alienation, depreciation of the personal in man as a result of creation of cultural and scientific institutions, which appear as the embodiment of collective perception. The leading approach to the study of this problem is the ascent from the abstract to the concrete, which makes it possible to comprehend the phenomenon of personal participation of man in the world on the whole, key essence of spirituality and the significance of its adequate interpretation in human existence in the modern world. This study also used the dialectical method and hermeneutical analysis of texts that relate to the problems of the metaphysical foundations of human personality in the modern world. It is spirituality that is currently undergoing a false interpretation, since spirit and mind are identified. Thus, the mind is a service tool of being as will and is placed in the sphere of culture. The spirit turns out to be utilitarian intelligence and is defined as the cultivation of certain values. The conducted analysis shows that the possibility of personal self-identification in the world is only possible thanks to the participation in existence, in that which forms and preserves the human essence and is the manifestation of its being.
\end{abstract}

\section{Introduction}

Turning to the problem of metaphysical foundations of human personality in the modern world is due to the transition to a new understanding of man, defined by his "cosmic" nature manifested in the participation in the world harmony integrity. Modern technogenic civilization appeals to man as a technical means, ensuring its relevance in technological, sign systems and programs that nourish the interests of certain group communities. Depersonalization of man entails various forms of alienation, which entail a spiritual crisis and man's loss of the boundaries of his "I". The semantic fullness of being and co-being of human existence ground the position of the personality in the world, the possibility of selfdetermination and human identity. Currently, there are many factors that have a devastating effect on the natural and social world and create all kinds of dangers for the spiritual and physical existence of man. So many researchers in a variety of areas of scientific knowledge

* Corresponding author: ttorubarova@rambler.ru 
pay close attention to understanding new challenges which arise precisely in our time and are characteristic for man-made civilization as they create not only real danger to public life, but also lead to the fundamental transformations in the field of culture, changing both understanding the essence of spiritual life of modern man and the very definition of spirituality. The studies of many authors have shown how the processes of globalization and fundamental changes in culture that affect the spiritual life of modern man are correlated. The idea appears in the work of S. Hofhuis [1].

It is technogenic factors that have a negative impact on modern man in the first place, that's why the attention of scientists in the study of personality is focused mostly on psychological changes which arise in connection with informational influence on the individual. The Turkish author N. Gokalp touches exactly upon this topic in his study. He considers the necessary factors in education, which, in his opinion, can significantly contribute to the creation of "necessary conditions for maintaining the integrity of personality" [2].

Man in today's world abides in a brand new social and cultural reality generating a different attitude to being, time, language. This circumstance prompts scientists who comprehensively study the problems of the human personality to rethink the fundamental approaches to its study. It is not surprising that at present personality can not be studied only within the boundaries of the scientific sphere, area or approach. That is why the transformation of sciences itself is necessary, as Wojciech J. Cynarski speaks in his work [3].

In a sense, the problem of man in culture is the topic of the collective work of researchers F. Fang, V. Schei, M. Selart, who find it necessary to use the concept of "cultural intelligence" in the study of the human personality, which entered into scientific circulation in the 2000's, after which the phrase "cultural intelligence" began to be used by scientists in various humanitarian fields of knowledge [4].

The above overview of contemporary research suggests that the problem of human personality in the metaphysical context has not been the subject of a special study. We have shown that the majority of scientists note the fundamental transformations taking place in recent times in the world on the whole, which in turn lead to changes in the existence of man, such as, for example, man-made factors that impact not only the existence of the individual, but of the whole natural world. This problem is well-represented in the studies by H. Nyborg [5] and J. Smart [6]. A wide range of works reflect possible assumptions regarding the cessation of life on earth for a variety of reasons. Such are, for example, the articles by M. Rampino [7].

So the purpose this research is to analyze the metaphysical foundations of human personality in the context of a spiritual crisis, depersonalization of man in an era of dominance of technorationality in the service of being as will.

\section{Materials and methods}

The key methods in this study were: the method of ascent from the abstract to the concrete, allowing to reveal the problem of human existence through the explication of its key constants: relation to being, time, language, and history in the context of understanding the phenomenon of spirituality. The methods of structural and functional analysis were used in the study of personal self-determination as the existential essence of human uniqueness. Also, the principles of the systematic approach were used in explicating the problem of the metaphysical foundations of human personality. The problems of self-alienation of man in the modern world and changes in the interpretation of the concept of "spirituality" that exist in the study of human personality were comprehended on the basis of the dialectical method. 


\section{Relevance}

The idea of the spiritual significance and meaningfulness of our life makes us think that we are called upon to accomplish something in the world, and something very important, and thereby realize ourselves in being. The fact of man's presence in the world is not evidence of him fulfilling his own life in its original manifestation and identification. For human existence is an act of co-being, requiring involvement in being, so to speak, "a mark by God or being". The question of the existence of our "I" forming a living origin, the quintessence of what we call the essential nature of man, cannot be removed from our metaphysical experience.

Each of us seeks to be something; otherwise, man is ambushed by a sense of his own insignificance, due to the loss of rootedness, any foundation, and as a result, a negative, revengeful attitude to everything around him. It is clear that human existence must be filled with meaning and will. But the inevitable immersion in the stream of time, the unavoidable fact of death, disease and aging, reminding us of the inevitability of this fact, constantly raises the question of the meaning of life.

Existential experience inevitably leads a person to the understanding that there is no difference between the fate of man and other living beings within the boundaries of earthly being "just as they die, so do these, and one breath in everyone, and there is no advantage for man over cattle" (Eccl. 3:19). And everything in the earthly world reminds man of his end.

Immersed in a stream of fleeting time, we feel like homeless and shelterless creatures, wanderers on earth. And in old age we inevitably come across a bitter thought that all active life is already in the past, and this thought causes constant irritation. Life can be meaningful if it is based on some eternal origin of being. And if this origin does not exist, then everything that happens in time, everything that arises and abides in time, somehow disappears. The meaning of human existence cannot be justified in any way by time, understood as continuous passage. And if this very being is understood, first of all, as the volition and action, then the meaning of human life should be something that man can confidently rely on, "that serves as a single, unchanging, absolutely solid foundation of his existence, testifying to his rootedness in his own foundational content and exceeding himself.

\section{Discussion}

The existence of man is due to the fulfillment of his own human origin, determined by the process of transcending. This process takes place in the kind of space, which is always based on a relation to something. Relation plays a key role not only in the self-identification of man as personality, but also in the constitution of his inner, meaningful world, which is called human life. Life is not just a process of entering into a series of occurring and succeeding each other episodes, phenomena, incidents, as if in a kaleidoscope. It's not just reproduction of certain event lines, but it is in fact, the entry into co-being. It is always based on a relation, or on something due to which such a relation is possible as a fundamental accomplishment, filling man's existence with energy and the very vitality that gives him meaning in relation to his actions and behaviour. This relation is associated with the requirement of individual effort, which opens to man as an opportunity, the opportunity to be. As M.K. Mamardashvili says: ".. the threads or atomic rods inserted into the boiler, allowing what happens next to happen, are always only a possible man - not some specific, present man, but that possible man who can make a turn, flash, settle in the space of some effort made by him that puts him "on the limit" of himself ..." [8]. In human existence this possibility opens as intuition to the attainment of life meanings giving impetus to the relations in which and by which man is restored to his own fundamental nature and event importance. 
We are used to thinking that every action is meaningful if it serves a reasonable purpose, if its rationality is recognized, once achieved in time, it turns out to be transient in time. Then life is just a process of living through one's life span, and when we become aware of it, then it often turns out to be a goal in itself for us. We are getting involved in an uncontrolled stream of events happening to us, the fleeting change of which turns into monotony and meaninglessness. Our existence in time eliminates any solid and stable foundation as evidence of inner satisfaction and the depth of being fulfillment. If the unity of the "I" and the world has only temporal character, then the world is generally outside of being and then hope for the future or the past is devoid of any meaning.

When we comprehend real things, we say that they are. But here we want to comprehend the essence of being, and it always turns out to be as if we are rushing into the void. It then turns into almost nothing, and yet we will never agree that what is in its wholeness is nothing. Being remains incomprehensible and is like almost nothing. Therefore, the word "being" remains empty for us. It does not mean anything real, tangible and material. As M. Heidegger notes: "We must learn to understand that this fact is not as harmless as it shows itself when it is first established. For, in the end, the point is not that the word "being" remains for us only a sound, and its meaning only a fog, but that we have fallen out of what this word is about, and we still do not see the way back; therefore, for no other reason, the word "being" does not correspond to anything anymore, and everything we take to is scattered like tufts of clouds in the light of the sun". "Heidegger asserts from the first line that being outside and beyond the cash goal" [9]. And F. Nietzsche was right when he said that such "lofty" concepts as being are the last real fumes of reality. He also argued that reasoning about being is a complete mistake. If in relation to metaphysical sphere the phenomenal world is reduced to nothing, then when this sphere itself is reduced to nothing, then only the phenomenal world as a possible place of Genesis remains, according to T.V. Torubarova [10]. So, the word "being" is an error and a fog. Such Nietzsche's reasoning about being is not accidental. Erroneous then is the question of being and nothing. But in any case foggy. Is this a flaw in being in itself? Or is it the unfortunate choice of the word and therefore it remains empty? Or should we ourselves feel guilty that, with all our efforts to be the center of reference of all things existing and with all our efforts to pursue all things existing, we inevitably fall out of being? Or else, can we say that it was not us, the current generation, or our ancestors who fell into error, but that the error lies in something that permeates the whole of Western philosophy from the very beginning, that is, it consists in such an event that we still can neither perceive nor understand, but which nonetheless happened, happened in the past, happens in our time and will happen in the future? Or maybe the whole point is that man, the great historical peoples and nations in their fundamental traditions and movements, have long fallen out of existence, not knowing it, and perhaps this is the main reason for the degradation of human existence? Or maybe the reason is that for many centuries some peoples or nations imagined themselves carriers of the historic mission? In the horizon of anthropocentrism such attitude to history was established, in which all history is the search for the perfection of human life, which is constantly distorted by class struggle. In Russia, the belief has always been strong that the whole world could be saved through it. The tragic collapse of ideals and dreams after the revolution and the period of domination of "real socialism" are explained as being ruled by two moments of truth: firstly, the plan itself for saving the world and man was fundamentally false; secondly, the human material of the "saviors" turned out to be unsuitable, endowed with a passionate will for power and domination. In their hatred of the past, they were blinded by their own projects. They opposed themselves and their aspirations to the whole past and the things fulfilled in actual reality.

These questions arise not from a special state of our consciousness but have a fundamental basis in being, in our participation in being. 
The question now is whether being is an empty word, or it is our spiritual destiny? This question arises constantly now, when technological expansion turns out to be unstoppable and continuously expanding, and when the task of the total organization of a "mass", "averaged" man, deprived of his spiritual roots and origins, comes to the foreground. The technology extends already to the near-Earth space, and now everything on earth, including its oceans and seas, is open to uncontrollable exploitation. Now any incident on earth is instantly communicated to the whole world. The virtual horizon fills the space more and more, taking over man's right to be himself. The human individuality is dispersed in the variety of "I", all kinds of social roles, identifying its bodily shape with some mechanisms, apparatuses, instruments. Time becomes only speed and instant, and time as history disappears from human life. A great person is an athlete, chess player or rock star. Mass and violent rallies become a condition for solving social and national problems, and corruption and crimes impose their own special world on everyone. This is a continuous eclipse of the world. Such an eclipse when the widespread destruction of the earth and the dispersal of the atmosphere already reach their irreversible limits, when people turn into such a mass that inevitably is attracted to total organization, when hatred, revenge and suspicion of everything free, creative and spiritual have already taken such proportions that the categories of pessimism and optimism are not just childish, but long ago absurd. The great decision must be carried out in terms of a new spiritual energy, which must be unfolded in a truly existential and historical way. But this means the need to return to the beginnings of our spiritual and historical existence in order to turn it into a new beginning. This is, perhaps, a really decisive form of history, because it begins in a fundamental event. This does not mean that, repeating our beginning, we must reduce it to the past. This is not about a well-known past that needs to be emulated. No, the beginning must be announced again, more radically. This is about a new questioning of being. For Nietzsche, being is an illusion, since it is incomprehensible at all. Being is indeed indefinite and vague for us, and for a long time already. But the point is not, according to M. Heidegger, that the word "being" is empty for us, but that we are thrown back from what this word says, thrown back into some kind of dead end of history, and therefore we cannot find a way back from this dead end to the true articulation of being. But the fact is that not a single person bears an "absolute" testimony, but every testimony has its own truth if it is expressed from the situation of its being. We know the law of logic, which Hegel constantly appealed to, and which states: the most comprehensive concept is the vaguest and empty in its content. And there is no more comprehensive concept than the concept of "being". This law is completely convincing, and therefore the question of being is vague for us. We ask: what is the meaning of the word "being"? This questioning seeks to restore the historical being of man now and here, and this always includes the future of beinghere in all historical integrity, in history as such a fundamental reality which is intended for us in our relation to being. The historical questioning of being is part of our history itself, moreover, of the current history when the following happen: the obscuration of the world as a result of hollowing out and dissipation of spirituality, distortion of it by false interpretations of spirit, among which we are able to allocate the following the main aspects. Firstly, spirituality is reinterpreted as intelligence, or spirit is interpreted as such rationality that is trying to put everything to experimental testing and mathematical calculus of things and possibilities of changing and supplementing them in the process of producing new things. Such rationality is determined by ordinary practice and the mass distribution of labor; it is subordinate to the possibility of organizing a mass person devoid of a personal origin. The spirit, falsified in the intelligentsia, is modified into a publicist, writer and esthete. Today's ordinary intelligentsia is only a semblance of spirit, masking its absence, since the spirit in the form of intelligentsia is reduced to the level of a service role (according to Lenin, serving the ruling class; according to K. Marx, a means of expressing a dominant ideology), to the 
level of easily memorized and reproducible means. The mask becomes an adaptive form of socialization of man, his participation in public space, and life turns into a role play. Such personalization is turning into a new form of human identity. "Exteriorization of the inner deprives a person of a full content, at the same time placing the subject in a subordinate position and leads to a crisis of human identity", as noted by Zhilina V. A., Hnykin D. A. [11].

Secondly, if spirituality is reduced to reason, then in case reason is connected with its use in organizing, regulating, and dominating the material conditions of production, as proclaimed by Marxism, or in case reason is connected with the ordering and explanation of all things existing which have already been established by us, as is the case in positivism, or if reason is applied to the organization and regulation of vital sources of masses - in all these cases the spirit as reason becomes a "superstructure", "epiphenomenon", an impotent superstructure of production of goods or the factual reality that is devoid of spirituality, and is taken as an actual reality. If we accept the spirit as reason, which takes place in Marxism, then it will be correct to state that, in the order of effective forces, reason should be lower in rank than material production. But this order turns out to be false if we understand the true essence of spirituality, for all bodily beauty and power, all ingenuity and authenticity of reason are based in spirit and spirituality, and only through the strength or impotence of spirit does the elevation and degradation of reason take place. Thirdly, in these false interpretations of spirituality, spirit as reason becomes a service tool; and in this kind of degradation of spirit as a means, the energy of the spiritual process, poetry and art, religion and statehood - all this is subject to conscious cultivation and planning. The energy of the spiritual process is dissipated in various divisions. And since the spiritual world becomes culture, thus the individual strives to improve itself in the creation and preservation of culture. "The importance of the principle of uniqueness, applied both to natural phenomena, cultural invariants, and to the human personality, is especially increasing in the age of homogeneity of the globalized world. Consumer society and global information networks give rise to the danger of creating a society where all states, national cultures and people find themselves with "one face", with stamped brains, thoughts, feelings, and abilities", writes Poroshenko Olga Yu. [12]. Culture itself is divided into various spheres of preference, which set their own standards for themselves, use them to live according to them. And these standards of production and consumption are called values. "In a consumer society in which there is no freedom from consumer coercion, the fear of failure in the process of self-fulfillment, which goes beyond over-consumption, generates in people a lack of freedom and a lack of desire to take responsibility in case of failure", writes Tsymbal E. A. [13]. Politics designed to guide and organize a mass person extends to culture, intervenes in it. Total politics is supported by a sense of danger, therefore, in its appeals, it mobilizes all means, including culture. It does not turn to culture for goals, it brings and distributes them itself and now teaches us what and how to write, compose and philosophize. The thirst for revenge and the indignation of the mass man, which is identified with the historical laws of the universe, is introduced into politics. Continuity is inherent in the spirit, while culture, divided into separate spheres, allows anyone who considers himself to be a minister of culture to completely identify with the momentary state of his national culture. And all that we now consider culture is no longer directly determined by the criterion of truth, for in the value relations a distorted relationship with the truth finds its place. But when lie becomes reality, then only we can finally find out about lie. In culture, the spirit as reason is inevitably subjected to processing, requiring equation and submission from one and all. But the spirit is not able to fulfill this requirement without losing itself. Humanity, like freedom, has now become values, but thereby the morality of humanity is being removed from reality, and spiritual life is perverted. One totalitarianism is replaced by another, and each feels itself a "reappraisal of all values," turning out to be nothing more than a "path to chaos". The present man has lost 
independence; he becomes strong only in conjunction, so Bolshevism is not a riot, not a random coup, but a stage in historical development. This is anti-personal collectivism with its inherent pronounced gross weight thinking. What is happening is interpreted by leaps and revolutions, a kind of concept of disasters. Cultural and scientific institutions are created as the embodiment of collective perception, as organs of processing and the direction of this perception into action. Ideas are produced by negative affects; they are a mirror image of these affects, which nevertheless need to be organized, mobilized and united into a powerful whole, which, aligned inside and out, thus is already processed for guidance. The action of the effect of revenge, producing the corresponding ideas, is expressed excluding the unsuitable, and attracting the suitable. And such spirit realizes itself as will, called upon to give ideological education a solid and unified form. And spirit-as-will subordinates reason to a vengeful affect. Affect has a hypnotic effect on reason. Affect actions are aimed at achieving power superiority and unity; this is a bundle of passions, which, subject to the will, find their ideological coat. Thinking permeated by a powerful negative affect receives an enviable unity in its corresponding ideology. Such thinking turns out to be compiled due to well-known ideas, since the affect inherent in it is always a compilation. Spirit devoid of an identity card turns into a seething magma of affects that feed an instinctive aversion to the excessively broad and the universal, for in everything there must be simplicity, which is required by the satisfaction of immediate animal needs. The genuine spirit becomes an unbearable burden for the mass person, therefore it allows itself to be destroyed in calculating and vengeful reason, which is always influenced by politics. In opposing the impact and influence of politics, cultural values retain their significance by limiting themselves to autonomous spheres, say, poetry for the sake of poetry (the concept of "pure poetry"), art for the sake of art, science for the sake of science. For example, considering the phenomenon of science, we define science as technical and professional knowledge oriented towards practical efficiency and as a cultural value in itself. Both of these dimensions are moving in the same direction of lowering the rank of false interpretation of spirituality and its dissipation. They differ only in one aspect. If in our time the technical and practical concept of science as a separate kind of specialization can claim a sincere and clear sequence, then the interpretation of science, on the other hand, as a phenomenon of culture and cultural value indicates a weakening of spirituality. The confusion of lack of spirituality today goes so far that even supporters of the technical and practical orientation of science are forced to directly recognize faith in science as a cultural value by this lack of spirituality. Therefore, in axiology today it is quite logical to "discuss not nature but the mechanisms of value formation", notes Nagoy F. N. [14, p.21]. Today the diversity of disciplines is held together primarily by technical dimension and practical effectiveness. And the awakening of spirituality cannot get its direction from such science, which in its disciplinary divisions is increasingly losing its rootedness in its essential basis.

And finally, in the false interpretation of spirituality, in which spirit is understood as reason, and reason is the service tool of being as will, and it is placed in the sphere of culture, spirit turns out to be a utilitarian intellect, spirit is defined as culture, that is, by cultivation of certain values. The world of changing values reproduces a man "without properties". "Touching upon the main problems of the modern global society, it should be noted the problem of invasion of technology in interpersonal relations, which creates qualitatively new forms in public communication, affects the deep spiritual, psychological, personal, ethical, political, economic, scientific and other spheres of human existence", write Ioseliani A.D., Tskhadadze N. V. [15]. Man as a project establishes new opportunities for self-fulfillment, where the boundaries of the personality are very shiftable. That is, the expansion of opportunities for identification happens at the cost of neglecting responsibility and sanity, the internal backbone of man that we call spirituality. Spirituality is not reduced to utilitarian 
intelligence, nor to irresponsible play of the mind, nor to limitless work of analysis and articulation of reality performed by practical reason. Even less it is the logos, but rather the fundamental and self-aware determination of unity with the essence of being. For, where spirituality is preserved, there all things existing as such become more and more substantial. This idea gets a special urgency in the light of the attempt to create "a postman - a future man with improved parameters, and even more so, an immortal person, in fact, a non-human, deprived of the fundamental foundations of our nature", write Zholobova Yu. V., Schastlivtseva, E. A. [16].

\section{Results}

To summarize all the above said, we note that comprehending all things in existence as such and our presence inevitably confronts us with the question of being and this question is one of the most essential and fundamental conditions for the awakening of spirituality and therefore for the original world of historical existence. This is necessary if the very danger of the obscuration of the world must be eliminated. The question of being is historical in itself, and it is important to take seriously precisely the fact that gives the question its necessary character, the fact that being is not just a word for us, the meaning of which is vanishing fog. And this fact is the state of our existence here, which reflects our entire constitution, that is, the way we constitute ourselves in relation to being. And the point here is not in psychology, but in the essential aspect of our historical reality. When we call it a fact that being for us is only an empty and foggy word, it means that something has already happened to us, and something very significant. As soon as the word "being" turns out to be empty for us, this means that the language itself is being frayed, which is used only as a means of communication and transfer of information, that is, as an indifferent tool. The indifferent attitude to the language and the hollowing out of the word "being", the deprivation of its appealing significance, are not just separate examples of general degradation. Rather, on the contrary, the perverted relation to being of all that exists is the real reason for the general distortion of our relation to ourselves and to anything whatsoever. We no longer know for ourselves what exactly is at stake in this relation. After all, the very fate of human existence is based on the relation to being, therefore, the question of being specifically involves us in the process of understanding who we are and what our existence is. Our relation to being, time and language depends on how we form ideas about everything that exists and what is happening. That is why it is important to understand what is now existentially necessary and metaphysically significant for us.

\section{References}

1. M. Boudry, S. Hofhuis, Cognitive Systems Research 52, 155-167 (2018) DOI: 10.1016 / j.cogsys.2018.06.010

2. N. Gokalp, Procedia - Social and Behavioral Sciences 47, 477-479 (2012) DOI: 10.1016 / j.sbspro.2012.06.683

3. W.J. Cynarski, Procedia - Social and Behavioral Sciences 149, 269 - 275 (2014) doi: 10.1016/j.sbspro.2014.08.228

4. F. Fang, V. Schei, M. Selart, International Journal of Intercultural Relations 66, 148-171 (2018) DOI:10.1016 / j.ijintrel.2018.04.002

5. H. Nyborg, Double relaxed Darwinian Selection Personality and Individual Differences 53, 118-125 (2012) DOI:10.1016 / j.paid.2011.02.031 
6. J.M. Smart, Acta Astronautica 78, 55-68 (2012) DOI:10.1016 / j.actaastro.2011.11.006

7. M.R. Rampino, Icarus 156, 562-569 (2002) doi:10.1006/icar.2001.6808

8. S.A. Gashkov, Herald of the Tomsk State University. Philosophy. Sociology. Political science 37, 141-148 (2017) DOI: 10.17223/1998863X/39/15

9. D.M. Spector, Philosophy and society 4, 48-70 (2018) DOI: 10.30884/jfio/2018.04.03

10. T.V.F. Torubarova, Bulletin of Vyatka State University 3, 4-12 (2018) DOI: 10.25730/VSU.7606.18.017

11. V.A. Zhilina, D.A. Hnykin, Chelyabinsk State University Bulletin. Philosophical sciences. Vestnik of Chelyabinsk State University 2(424), 51-61 (2019) DOI 10.24411/1994-2796-2019-10208

12. O.Yu. Poroshenko, Izvestia of Saratov University. New series. Philosophy series. Psychology. Pedagogy 19(3), 277-281 (2019) https://doi.org/10.18500/1819-76712019-19-3-277-281

13. E.A. Tsymbal, Scientific thought of Caucasus 2, 26-28 (2018) DOI: 10.18522/20720181-2018-94-2-26-28

14. F.N. Nagoy, Perm University Herald. Series «Philosophy. Psychology. Sociology» 1, 20-28 (2017) DOI: 10.17072/2078-7898/2017-1-20-28

15. A.D. Ioseliani, N.V. Tskhadadze, Economic security bulletin 2, 368-373 (2019) DOI: 10.24411/2414-3995-2019-10124.

16. Yu.V. Zholobova, E.A. Schastlivtseva, Vestnik of Vyatka State University 2(132), 1422 (2019) DOI: 10.25730/VSU.7606.19.014 